\title{
Judeoconversos burgaleses a fines de la Edad Media*
}

\section{Converted Jews of Burgos at the end of the Middle Ages}

\author{
RICARDO MUÑOZ SOLLA**
}

\begin{abstract}
RESUMEN
La minoría judeoconversa de Burgos sigue siendo un difícil objeto de estudio documental. Si exceptuamos la singular y determinante figura de Šělomoh ha-Levi I

Pablo de Santa María y de sus descendientes, se desconoce prácticamente todo sobre el número y elementos distintivos del grueso de la población conversa. Este artículo pretende aproximarse al problema converso burgalés a través de un análisis actualizado de los factores que puedan explicar la progresiva integración de esta

minoría en la estructura social de la ciudad. Las disposiciones reales, municipales y eclesiásticas sobre cómo afrontar las conversiones que se sucedieron desde finales del s. XIV permiten comprender mejor los motivos del reducido número de judaizantes que fueron procesados por el Santo Oficio, tal y como se confirma a través de documentación inédita relacionada con la actividad inquisitorial en Burgos y que se recoge en forma de apéndice.
\end{abstract}

\section{PALABRAS CLAVE}

Burgos, judeoconversos, Inquisición, Baja Edad Media.

\begin{abstract}
The converted Jewish minority of the city of Burgos is still a difficult subject of documentary research. Except for the singular and decisive personality of Šělomoh ha-Levi / Pablo de Santa María and his descendants, the number and distinctive signs of its converted inhabitants remain unexplored. This article aims to approach the Converso problem in Burgos through an updated analysis of the factors that could explain the progressive integration of this minority within the social structure of the city. The royal, local and ecclesiastical regulations on how to cope with the conversions that took place from the end of the 14th century help to understand the reasons for the scarce number of Judaizers that were prosecuted by the Holy Office, as is confirmed through documents, so far unknown, related to inquisitorial activity in Burgos, which are compiled as an appendix to this article.
\end{abstract}

\section{KEY WORDS}

Burgos, converted Jews, Inquisition, Later Middle Ages.

* Fecha de recepción del artículo: 2009-10-9. Fecha de aceptación del artículo: 2010-2-15.

** Universidad de Salamanca. C.E.: solla@usal.es 
La comunidad judía de Burgos ha sido y sigue siendo paradigma de la vitalidad y fuerza creativa de la que gozó el judaísmo castellano durante la plena Edad Media. No es mi objetivo en esta ocasión insistir en el desarrollo económico, social y cultural que alcanzó a finales del s. XIII, como lo puede atestiguar, por ejemplo, la presencia en la ciudad de varios miembros de notables familias de estirpe judía como los Abulafia y los Bienveniste o, en el campo intelectual, el influjo de las doctrinas de rabí Mošeh de Burgos entre los círculos cabalísticos de Castilla. Desde mediados del s. XIV, sin embargo, esta próspera aljama tuvo que afrontar momentos difíciles. La conversión al cristianismo de varios de sus líderes, las revueltas populares de 1391, las subsiguientes conversiones que estos hechos provocaron y la paulatina migración de pobladores judíos a otros lugares del obispado burgalés, son factores decisivos para comprender su decadencia a lo largo del s. XV.

De las últimas actuaciones de sus judíos en la ciudad, ya en vísperas de la Expulsión, dí cuenta en un estudio en el que pude reconstruir el destino de la sinagoga burgalesa desde 1492 hasta $1501^{1}$. En ese momento, y teniendo en cuenta la escasez de noticias acerca del grueso de población judeoconversa en la ciudad, me pareció reveladora la presencia de algunos conversos que tenían sus casas próximas a la sinagoga en la denominada Villa Nueva, - un barrio ya muy deteriorado en el que vivían entremezclados algunos judíos y conversos-, así como el conocimiento que muchos de ellos demostraban tener acerca del edificio.

Desde mi punto de vista, daba la impresión de que, al igual que ocurre a finales del s. XV con la población judía, la presencia de los judeoconversos burgaleses parecía diluirse poco a poco; en especial, los documentos históricos apenas aportan datos sobre la generación conversa de 1492. Y no deja de percibirse como algo extraño, sobre todo si se tiene en cuenta la creencia aceptada, y tal vez poco matizada, de que por esas fechas y al igual que ocurrió en movimientos confesionales anteriores, en Burgos la mayoría de judíos pasó a engrosar las filas de neófitos al cristianismo ${ }^{2}$. Resulta, por lo tanto, lícito preguntarse por qué se ignora tanto sobre este último período del judaísmo burgalés, qué pudo favorecer la ausencia de un verdadero problema converso en la ciudad y, sobre todo, cuál pudo ser la dimensión histórica de estos conversos y de sus descendientes, de los que, en tantas ocasiones, no conocemos apenas nada más que sus nombres. Desde esta perspectiva, me propongo reflexionar brevemente sobre las posibles causas que han contribuido a conformar esta silenciosa presencia de una parte importante de la población judeoconversa en la ciudad de Burgos a finales del S. XV,

1 Vid. R. Muñoz Solla, «El destino de la sinagoga de Burgos después de 1492», Boletín de la Institución Fernán González LXXXVI, 234 (2007/1), pp. 87-121 y 235 (2007/2), pp. 337-375.

2 Así lo han afirmado T. López Mata, "Morería y Judería», Boletín de la Real Academia de la Historia CXXXIX (1951), pp. 335-384, en concreto p. 384 y F. Cantera Burgos, «La judería de Burgos», Sefarad XII (1952), pp. 54-104, en concreto, p. 103. 
valorando las noticias con las que contábamos hasta ahora y aportando, en la medida de lo posible, nueva documentación.

Frecuentemente se ha afirmado que el problema converso en el norte de Castilla no se manifestó con la misma intensidad y crudeza que en tierras andaluzas, apoyando así la idea que expresaba el anónimo autor del Libro del Alborayque sobre la desigual extensión de la herejía judaizante: «Esto no deven de haver por reproche los buenos de los conversos de Castilla antes lo tienen por honrra, que si huviesen de ser juzgados con los conversos andaluces y aun toledanos, todos serían condenados por malos erejes, lo qual no es ansí mas lo contrario, ca así en Castilla la Vieja, Burgos, Palencia, Valladolid, Zamora, Salamanca y León apenas hallarán de ellos los conversos naturales ereges ningunos, así en el reyno de Toledo, Murcia, Andalucia y Estremadura apenas hallaredes de ellos xristianos fieles»3. Había, sin duda, diferencias profundas entre conversos de unas y otras regiones, ya que las circunstancias de cada lugar variaron considerablemente, favoreciendo en unos casos, la asimilación, y en otros, la segregación de los mismos. Para el caso de Burgos, se puede aceptar, en líneas generales, que lo que predominó fue la integración de la minoría conversa ya desde épocas muy tempranas. Se trató de una tendencia fuerte y muy arraigada que se prolongó desde finales del s. XIII (recuérdese la temprana conversión de Abner de Burgos ${ }^{4}$ ) hasta el ocaso de la judería burgalesa.

Varios factores contribuyeron a hacer más fácil este tránsito de la mentalidad del recién convertido a los espacios simbólicos del cristiano viejo. El más importante tiene que ver con la proyección socieconómica y cultural que alcanzaron muchos linajes conversos de Burgos. Es, con mucho, el aspecto mejor conocido de la historia conversa de la ciudad, gracias a los trabajos paradigmáticos que sobre la familia de los Santa María realizaron L. Serrano Pineda ${ }^{5}$ y F. Cantera Burgos ${ }^{6}$. La

\footnotetext{
3 «Libro llamado del Alborayque«, editado por N. López Martínez, Los judaizantes castellanos y la Inquisición en tiempos de Isabel la Católica, Burgos 1954, Apéndice IV, pp. 391-404. La cita corresponde a la p. 402. El texto ha sido objeto de varias ediciones y estudios: vid. D. Gitlitz, «Hybrid Conversos in the "Libro llamado el Alboraique», Hispanic Review 60/1 (1992), pp. 1-17; Alborayque, Dwayne E. Carpenter, Mérida 2005, 2 vols, sobre un manuscrito hallado en Barcarrota (Badajoz); H. Salvador Martínez, Convivencia en la España del s. XIII. Perspectivas alfonsíes, Madrid 2006, pp. 411-422. P. Bravo Lledó - M. F. Gómez Vozmediano, «El Alborayque: un impreso panfletario contra los conversos fingidos de la Castilla tardomedieval», Historia, Instituciones, Documentos 26 (1999), pp. 57-83, el texto en apéndice, pp. 72-83.

4 Para una bibliografía actualizada de su trayectoria personal e intelectual, vid. F. Gómez Redondo, «Alfonso de Valladolid», Historia de la prosa medieval castellana, II, Madrid 1999, pp. 1752-1761 y C. Alvar - J. M. Lucía Megías (eds.), Diccionario filológico de Literatura medieval española. Textos y transmisión, Madrid 2002, s.v. «Alfonso de Valladolid», pp. 140-152.

5 Don Pablo de Santa María, Gran Rabino y Obispo de Burgos, Burgos, 1941.

6 El estudio de este último sobre Alvar García de Santa María y su familia publicado en 1952 encabeza la reimpresión de su Obra Selecta que ha iniciado en 2007 la Fundación Cultural «Profesor Cantera
} 
omnipresencia de los Santa María-Cartagena en la estructura política y social de la ciudad durante la primera mitad del s. XV es indiscutible: resulta muy difícil no encontrarse con alguno de sus miembros cuando se estudian aspectos concretos de la historia urbana de este período, tanto en el ámbito concejil como en el eclesiástico. Como es bien sabido, muchos de ellos fueron, regidores, escribanos, obispos y humanistas, que lograron un considerable nivel de riqueza y un reconocido prestigio ${ }^{7}$. Pero lo que me interesa destacar, al margen de las aportaciones personales e intelectuales de cada generación, es que su estratégico ascenso social no se vio especialmente dificultado por tener orígenes judíos o ser descendientes de conversos ni provocó enconados conflictos con la oligarquía cristianovieja, a diferencia de lo que ocurrió con frecuencia en otras ciudades, donde la enemistad entre ambos grupos fue manifiesta. Hubo casos concretos donde se comprueba el especial interés de esta familia por asegurar a sus miembros una estabilidad religiosa acorde con su estatus social y alejada de presiones anticonversas. A ello podría responder el paso de Teresa de Cartagena, nieta de Pablo de Santa María, de la orden franciscana de Santa Clara a la orden cisterciense de Santa María la Real de Huelgas, según proponen D. Seindespinner-Núñez y Y. Kim en un reciente estudio sobre su figura ${ }^{8}$. Hay que tener en cuenta, por lo tanto, que el linaje de los Santa María representaba un modelo de conducta cristiana que debió de influir mucho sobre el conjunto de la población conversa ${ }^{9}$. Pero también conviene advertir que el caso de los Santa María no fue excepcional. La ascendencia conversa de muchas familias burgalesas de renombre como la de los Maluenda, Polanco, Espinosa, Quintanadueñas, del Peso, Salon o Salamanca, era bien conocida por muchos sectores del poder local. A pesar de ello, en muy pocos casos esto supuso una verdadera traba para que estas sagas familiares prosperasen como lo hicieron durante decenios.

Indudablemente, en todo ello influyó el hecho de que durante los siglos XV y XVI Burgos fuese la gran metrópoli que organizaba los intercambios entre Castilla y Europa, en su doble vertiente comercial y financiera. La actividad mercantil dinamizó de forma extraordinaria la vida ciudadana, favoreciendo el desarrollo artístico y los intercambios culturales. Se había creado una compleja red de relaciones comerciales que comprendía desde las principales plazas del norte de Europa (Brujas,

Burgos", bajo la coordinación de Y. Moreno Koch y M. ${ }^{a}$ F. García Casar; vid. F. Cantera Burgos, Alvar García de Santa María y su familia de conversos. Historia de la judería de Burgos y de sus conversos más egregios. Obra Selecta (reimpresión), vol. I, Miranda de Ebro 2007. Hasta la fecha, se ha reeditado también la obra Abraham Zacuto. Siglo XV, Miranda de Ebro 2008; y Judaizantes del arzobispado de Toledo habilitados por la Inquisición en 1495 y 1497, con la colaboración de Pilar León Tello, Miranda de Ebro 2009.

7 Vid. la lograda síntesis de I. Rilova Pérez, Burgos en la primera mitad del siglo XV: la ciudad, la iglesia y la familia conversa de los Cartagena, Burgos 2008, en especial, pp. 247-279 y el notable estudio de L. Fernández Gallardo, Alonso de Cartagena. Una biografía política en la Castilla del siglo XV, Valladolid 2002.

8 «Historicizing Teresa: Reflections on new documents regarding sor Teresa de Cartagena", La Corónica 32.2 (2004), pp. 121-150, en especial, pp. 123-135.

9 Cfr. C. Carrete Parrondo, Fontes Iudaeorum Regni Castellae II. El Tribunal de la Inquisición en el Obispado de Soria (1486-1502)[=FIRC, II] , Salamanca 1985, § 442, p. 442. 
Amberes, Londres, Burdeos), Italia y Portugal, hasta el mercado interior representado por las ferias de Medina del Campo, Villalón y Medina de Ríoseco y por centros de exportación internacional como Sevilla, lo que situaba a Burgos en una posición excepcional respecto a otras ciudades. La mirada de la ciudad hacia el exterior, más allá de la tradicional economía del reino, fue una empresa común a la que grandes compañías de mercaderes conversos lograron sumarse con facilidad. El caso de la familia de los Bernuy, de origen abulense y estudiado por $\mathrm{H}$. Casado Alonso ${ }^{10}$ es buena muestra de esta particular seña de identidad de las oligarquías conversas mercantiles, que lograron enriquecerse y, en muchas ocasiones, ennoblecer su linaje con la obtención de hidalguías y privilegios nobiliarios. Su éxito económico y su ascenso social logró eclipsar su procedencia, que se fue diluyendo en el tiempo ${ }^{11}$.

La progresiva pérdida del estigma converso de este modo tan poco traumático, parece haber sido también la tendencia entre mercaderes y artesanos de más humilde condición. Algunos conversos de la primera mitad del s. XV, cuyos nombres y actividades están bien documentados ${ }^{12}$, abandonaron sus antiguas casas para establecerse en otros lugares de la ciudad, lo que les permitiría cierto anonimato, sin tener que abandonar por ello sus actividades profesionales. Algo muy similar ocurrió con algunos conversos de la generación de 1492 que formaron parte del gremio de los ropavejeros, o traperos de viejo. En 1502 éstos se habían establecido en los barrios bajos, distanciándose así de lo que fue la antigua judería ${ }^{13}$. No

10 «De la judería a la grandeza de España. La trayectoria de los Bernuy, una familia de mercaderes. Siglos XIV-XIX», Bulletin of the Society for Spanish and Portuguese Historical Studies, vol. XXII/2 (1997), pp. 9-27; y su más reciente, El Triunfo de Mercurio. La Presencia Castellana en Europa (siglos XV y XVI), Burgos 2003, pp. 137-162.

11 Sobre las actividades de algunas de estas familias, vid. B. Caunedo del Potro, «Los negocios de Diego de Soria, mercader burgalés», La Ciudad de Burgos. Actas del Congreso de Historia de Burgos, Madrid 1985, pp. 163-172; «Acerca de la riqueza de los mercaderes burgaleses: aproximación a su nivel de vida», En la España medieval 16 (1993), pp. 97-118; «Factores burgaleses ¿privilegiados o postergados?», En la España medieval 21 (1998), pp. 77-113; e H. Casado Alonso, «Una familia de la oligarquía burgalesa del siglo XV: los Alonso de Burgos-Maluenda», La Ciudad de Burgos. Actas del Congreso de Historia de Burgos, Madrid 1985, pp. 143-162.

12 Vid. H. Casado Alonso, «Crecimiento urbano y mercado inmobiliario en Burgos en el siglo XV», Mercado inmobiliario y paisajes urbanos en el Occidente europeo. Siglos XI-XV. Actas de la XXXIII Semana de Estudios Medievales de Estella, 17 al 21 de julio de 2006, Pamplona 2007, pp. 631-690, en concreto, p. 650, n. 34. A la relación de conversos estudiada por este autor, entre la que destacaba la familia de los zapateros de los Garcimuñó, pueden incluirse los siguientes: Juan, Alfonso y Pedro, maestres conversos. El Cabildo de la Catedral les concedió desde 1398 a 1401 una limosna de varias fanegas de trigo, RR-2, fols. 114, 131, 159v-160. Vid. también C. Carrete Parrondo, FIRC II, § 115, p. 62: Velasco Martínez, Ferrand Martínez, «se tornaron christianos quando lo de fray Viçente», tíos de doña Jamilia, mujer de Abrahán aben Latsa, vecina de Soria. «Eran vesinos de Burgos e heran mercaderes». "Velasco Martines tuvo vn fijo, que se llama Velasco Martines, como el padre, que no sabe sy es biuo; es que Ferrando Martines non ovo fijos, e questán en Burgos enterrados». Ayudaron a casar con cierto dinero a dos sobrinas suyas.

${ }_{13}$ Según provisión dada el 14 de febrero de ese año por los Reyes Católicos para que ciertas personas y oficios se subiesen a vivir y tener sus tiendas en lo alto de la ciudad: «los roperos de viejo, que heran los nuevamente convertidos, estauan mucho mejor en lo baxo que no en lo alto a causa que avía sido judería donde los mandava poner y que cada vno hera libre para bebir donde quisiesen de muros adentro de la dicha çibdad», Archivo Municipal de Burgos [=AMB], Historica 3138, cit. T. López Mata, «Morería y Judería«, p. 384 y A. C. Ibáñez Pérez, Arquitectura civil del s. XVI en Burgos, Burgos 1977, p. 47 , n. 82. 
cabe duda de que tanto la dispersión de estos conversos en el entramado de nuevas calles y barrios de la ciudad, como la movilidad geográfica de la que hacen gala los grandes mercaderes burgaleses les permitía equipararse con mayor facilidad con el resto de los habitantes, permitiendo así una integración social y religiosa mucho más rápida con su medio.

En otro orden de cosas, hay que destacar asimismo la decidida política de protección que la Corona adoptó desde los primeros momentos en que irrumpió el problema de las conversiones en la ciudad. Durante los años de 1390 a 1392, varias cédulas reales firmadas por Enrique III expresaban abiertamente la voluntad del rey de defender a los judíos burgaleses de los ataques, robos y asaltos que se produjeron en la judería así como la de salvaguardar los derechos de los recién convertidos. Por temor a la muerte muchos judíos abandonaron la judería siendo recogidos en «las casas de algunos omes buenos de la dicha cibdat». Algunos ya no regresarían, pues optaron por la conversión; pero aquellos que quisieron volver a habitarla contaron para ello con la protección del monarca ${ }^{14}$. Asimismo se trató de limitar las presiones que ejercían los cristianos viejos y algunos recién convertidos contra la población judía, en un intento de favorecer las conversiones voluntarias. Se señalaba así «que non manda ni consienta nuestra ley que alguno sea tornado a la fe católica por fuerça e contra su voluntad. Los judíos que por su propia voluntad sý quisieren tornar a la fe de los cristianos es bien de los recibir e tornarles cristianos, e no faser premia a los que de su propia voluntad non se conuertie$r e n^{15}$ ». Con todo, los conflictos no se resolvieron fácilmente. El rey hubo de intervenir por tercera vez para defender a los conversos que vivían en la colación de Santa María la Blanca, próxima a la judería. Exigía en esta ocasión que se les tratara por igual cuando fueran presos, enviándoles a la cárcel de la ciudad y no a cárceles privadas, como se hacía con los nuevamente convertidos. La consideración de Enrique III sobre sus derechos era clara y contundente: "Deuedes tractar asý como a hermanos e deuen gozar de vuestros preuellejos, libertades e buenos usos e costumbres ${ }^{16}$ 》.

Decisiones del mismo modo prudentes respecto a cómo actuar con los recién convertidos fueron tomadas por distintos órganos de poder local a lo largo del s. XV. Tanto el cabildo catedralicio como el concejo de Burgos afrontaron en varias ocasiones esta cuestión con acertado criterio, valorando los efectos de conversiones precipitadas o rechazando, en su caso, a aquellos neófitos de dudosa reputación.

En el sínodo celebrado en Burgos en julio de 1474 y presidido por el obispo don Luis de Acuña, se trató de cómo proceder con los bautismos de judíos y de moros ${ }^{17}$. Según se informaba, "algunos judíos o moros, mayores de los dichos sie-

14 AMB, Historica 2960.

15 AMB, Historica 2961.

16 AMB, Historica 2702.

17 A. García y García (ed.), Synodicon Hispanum, o.c. VII, pp. 196-230. Vid. también, N. López Martínez, «Don Luis de Acuña, el Cabildo de Burgos y la Reforma (1456-1495)«, Burgense 2 (1961) pp. 187- 
te años, estando con sus padres e parientes e con otras personas con quien viven, no movidos con la voluntad e conoscimiento que dichos son, antes por enojar a los dichos padres e parientes o aquellos con quien están, e porque no los osen castigar e corregir de sus vicios, amenazando que se tornarán christianos o por otros muchos respectos, vienen [a] pedir baptismo e los clérigos, incontinente, los baptizan; de lo cual se sigue que el tal baptizado, en cuanto a su voluntad no es verdadero christiano». Luis de Acuña, atento a las consecuencias que podían acarrear estas conversiones simuladas, prohibía administrar el bautismo tan a la ligera, recomendando el examen minucioso de los motivos del converso así como la previa instrucción del futuro neófito en la doctrina cristiana. En los casos dudosos, se recomendaba también la consulta a los curas, obispos o a sus provisores. Todas ellas fueron medidas excepcionales que demuestran cierta sensibilidad por parte del cabildo a la hora de tratar esta cuestión; resulta difícil encontrar en otros lugares formulaciones tan precisas sobre las condiciones óptimas del bautismo, si bien es cierto que no sabemos si se llevaron a la práctica. En este sentido, hay que admitir, que hubo una distancia insalvable entre el discurso teológico y su aplicación práctica ${ }^{18}$. Esta última estuvo condicionada por planteamientos más radicales, que se concretaron, ya a mediados del s. XVI en estatutos de limpieza de sangre. Curiosamente, en el cabildo burgalés, se evitó su establecimiento en 1550 y en 1584-1585, gracias a la intervención de prebendados de origen converso ${ }^{19}$.

La situación provocada por la Expulsión de 1492 así como las conversiones precipitadas de aquellos judíos que decidieron permanecer en la ciudad obligó a las autoridades locales a tomar medidas menos comprensivas que las anteriormente citadas $^{20}$. En los años posteriores a 1492, cuando realmente se tomó conciencia de la existencia de una nueva generación de conversos y del problema de los judaizantes, el regimiento burgalés tomaba la determinación de controlar la llegada a la ciudad de otros vecinos conversos. En el mes de mayo de 1493 mostraba su preocupación porque «algunos malos christianos» venían a instalarse en la ciudad. En ese mismo mes se pedía también una averigüación sobre el origen converso de un preso que estaba en la cárcel pública que aseguraba haber sido judío, a pesar de que «non muestra ni trahe testimonio dello e se presumió ser falsedad»²1. En oc-

317, en especial, pp. 261-262; idem, «Sínodos burgaleses del siglo XV», Burgense 7 (1966), pp. 212-406; G. Martínez Díez, "Del Concilio IV de Letrán al Renacimiento", en Historia de las diócesis españolas. Burgos. Osma-Soria, Santander, B. Bartolomé Martínez (coord.), Madrid 2004, p. 120.

${ }_{18}$ Sobre esta cuestión, vid. A. Alcalá, «Tres cuestiones en busca de respuesta: invalidez del bautismo 'forzado', 'conversión' de judíos, trato 'cristiano' al converso", A. Alcalá (ed.), Judíos. Sefarditas. Conversos. La expulsión de 1492 y sus consecuencias, Valladolid 1995, pp. 523-544.

19 Vid. N. López Martínez, «El Estatuto de Limpieza de Sangre en la Catedral de Burgos», Hispania 18 (1958), pp. 54-81.

${ }_{20} \mathrm{El}$ acontecimiento, sin duda, tuvo cierta repercusión en Burgos; se reflejó, por ejemplo, en el libro de Actas Capitulares de ese año. El mes de mayo estaba encabezado por el siguiente apunte: «Este año y en fin deste mes mandaron los reyes nuestros señores don Fernando y doña Isabel que saliesen todos los judíos de Castilla y ansí se fueron y muchos se tornaron christianos", Actas Capitulares, 1492, fol. $15 \mathrm{v}$.

${ }^{21}$ AMB, 22 de mayo de 1493, fol. 47v-48 r. 
tubre de ese mismo año, y a pesar de las disposiciones de protección que dictaron los monarcas, se acordó solicitar que ningún cristiano nuevo foráneo pudiera vivir en Burgos porque dañaba la buena fama de la ciudad ${ }^{22}$. La presencia conversa comenzaba a sentirse como algo incómodo que era preferible evitar o, por lo menos, regular mucho mejor. Varios acuerdos vuelven a reflejar esta preocupación por la dañada imagen que un excesivo y descontrolado número de neófitos podría ocasionar en la ciudad ${ }^{23}$. Así, el 13 de octubre de 1499, se exigía que los nuevos convertidos trajeran los títulos que atestiguaban que eran cristianos, conforme se indicaba en una pragmática promulgada por los Reyes Católicos ${ }^{24}$ y se aludía también a la obligación que ellos tenían de "se ynformar en la fee algunos días de la semana» ${ }^{25}$.

\section{III}

Muchas de las disposiciones municipales reflejan el creciente recelo hacia la población conversa. Probablemente, ello estuvo motivado por las actuaciones inquisitoriales que se habían realizado en Burgos contra presuntos judaizantes y otros herejes. Desconocemos gran parte de lo que ocurrió a este respecto, debido a la práctica ausencia de documentación relativa al tribunal de Valladolid ${ }^{26}$, pero se puede afirmar que la Inquisición de Burgos era ya activa el 20 de octubre de 1489 y que era un tribunal independiente que ejercía su jurisdicción en la ciudad y en todo el obispado burgalés. La última alusión a su actividad antes de anexionarse al tribunal de Valladolid-Palencia, data del mes de julio de 1495, siendo el

22 AMB, 3 de octubre de 1493, fol. 77v: «Los dichos señores dixeron que por quanto a esta çibdad binieron gentes de las que nuevamente se tornaron christianos en lo qual biene grand perjuysyo a la dicha çibdad e a la buena fama della e porque sus altesas an escripto al señor corregidor que den fabor e ayuda a los tales christianos para que ninguno los faga enojo por venir a nuestra santa fee catolica e que los ynformen en la fe nueva que sean personas para ello e por quanto sus altesas en esto de la çibdad non fueron ynformados, y [sic] acordaron de suplicar a sus altesas manden que ninguno de los estrangeros nuevos christianos puedan entrar ni biuir en esta çibdad. E para saber los nuevos christianos que en esta çibdad ay dieron a cargo para lo ver a los señores Martín Sala, Pero de la Mota e Alonso de Villanueva».

${ }_{23}$ Vid. J. A. Bonachía Hernando, «'Mas honrada que ciudad de mis reinos': la nobleza y el honor en el imaginario urbano (Burgos en la Baja Edad Media)», en J. A. Bonachía (coord.), La ciudad medieval. Estudios de Historia medieval, Valladolid 1996, pp. 169-212, que cita algunas de estas decisiones de las Actas.

${ }^{24} \mathrm{AMB}, 13$ de octubre de 1499, fol. $111 \mathrm{r}$ : «[al margen] que los nuebos convertidos a nuestra santa fee traygan los títulos que tienen que son christianos. Acordaron que todos los nuebos convertidos dentro de seys días traygan los títulos que tienen de ser christianos conforme a la pramática de sus altesas ante la justicia e ante los señores comendador Juan Alonso de la Mota, alcalde merino e a don Diego Osorio".

25 AMB, 13 de octubre de 1499, fol. 112 r.

26 La documentación más temprana se encuentra en AGS, Patronato Real, leg. 28, exp. 73, fols. $1103 r$ - 1110 r, legajo editado por C. Carrete Parrondo, FIRC II, referido al obispado de Soria. Se trata de una copia de los libros de testificaciones, titulado «Libros de Burgos». Hay noticias de su actividad en Briviesca, Frías, Santa María del Campo, Cerezo, Hojacastro, Arcos, Covarrubias, Miranda de Ebro, Catrojeriz y Burgos. Parte de su contenido ha sido analizado por N. López Martínez, Judaizantes e Inquisición en la Ribera del Alto Duero (1486-1502), Burgos 2005. 
bachiller Hernando de la Torre inquisidor y juez de bienes confiscados de Burgos y su obispado ${ }^{27}$.

Durante estos años, la ciudad no sufrió el rigor inquisitorial que se observa en otros lugares. Junto al imparable proceso de asimilación de gran parte de la minoría conversa que hemos apuntado, hay que tener en cuenta también su temprana dependencia del tribunal vallisoletano a través de los comisarios de distrito cuyas ocasionales visitas no ayudarían demasiado a controlar el territorio ${ }^{28}$. Los inquisidores, en definitiva, no demostraron mucho interés por una ciudad donde la presencia de judaizantes, según apuntan todos los datos, fue poco notoria. A este respecto, A. Domínguez Ortiz ${ }^{29}$ argumentaba con implacable lógica que si el Santo Oficio hubiera querido atacar sistemáticamente a todos los conversos sin hacer distinción alguna entre ellos y enriquecerse con sus despojos, no habría tenido mejor oportunidad que proceder contra el poderoso e influyente foco de conversos burgaleses; y sin embargo, no lo hizo.

Es cierto que en Sevilla hubo ciertas actuaciones contra mercaderes de origen burgalés establecidos en la ciudad por razones económicas ${ }^{30}$. Algunos de ellos estuvieron vinculados con el grupo de conversos sevillanos con quienes compartían lugar de residencia en la colación de Santa María y cuya persecución, según ha estudiado J. Gil ${ }^{31}$, fue implacable. Pero al margen de estos casos, el resto de mercaderes burgaleses de los que tenemos constancia, no tuvo encontronazos con la Inquisición. Ocasionalmente, aparecen en documentación inquisitorial no como procesados sino como testigos de abono que declaran a favor de conversos vallisoletanos, con quienes tuvieron trato comercial, de amistad y, en algún caso, de parentesco. Estas declaraciones, que dio a conocer en su día N. López Martínez ${ }^{32}$, se realizaron en Burgos en 1491 para ser incorporadas a las causas contra los judaizantes Diego Luis de la Serna, Pedro López de Calatayud y el cambista Alonso de Verde, todos mercaderes vecinos de Valladolid, y ofrecen interesantes detalles

27 Vid. J. Contreras - J. P. Dedieu, «Geografía de la Inquisición española: la formación de los distritos: 1470-1820», Hispania XL (1980), pp. 37-93, en concreto, pp. 51-52. Sobre la actividad de este inquisidor en Burgos, vid. ACB, RR-26, fol. 182-183; RR-28, fol. 281v-282; RR-30, fol. 426, 427-428, 460. El 10 de junio de 1497, el bachiller informaba al cabildo de su partida de la ciudad, RR-31, fol. 347.

28 Vid. A. Salvá, Páginas histórico-burgalesas. Fueros, hermandades e inquisición, Burgos 1907, pp. 127-181.

29 «Las 'presuntas' razones de la Inquisición», J. Pérez y B. Escandell (eds.), Historia de la Inquisición en España y América, Madrid 2000, III, pp. 57-82, en concreto, p. 71.

30 Posibles conversos burgaleses fueron Antón de Soria, ropero, acusado de «que por espacio de un año tovo la creençia de la ley de Moyses»; Gonzalo de Contreras, estante en Sevilla en 1469 y condenado por hereje en Segovia. Al margen de las actuaciones inquisitoriales, se mantuvo el escribano Gonzalo de Burgos, hijo de Francisco Rodríguez de Santa María, vinculado a los Cartagena y que se estableció finalmente en Gran Canaria, vid. N. Palenzuela Domínguez, Los mercaderes burgaleses en Sevilla a fines de la Edad Media, Sevilla 2003, pp. 45-48.

31 Los conversos y la Inquisición sevillana, 8 vols, Sevilla 2000-2003.

32 «Testificaciones inquisitoriales de mercaderes burgaleses en 1491», Burgense 14 (1973), pp. 543566. He consultado los borradores que se conservan en el ACB, Libro de escripturas de diferentes notarios, que no tocan a esta iglesia desde el año 1490, s.n. El autor volvió sobre el tema en uno de sus últimos artículos, «Mercaderes castellanos bajo sospecha de judaizar (a.1491)», J. A. Escudero (ed.), Intolerancia e Inquisición, vol. I, Madrid 2005, pp. 389-414. 
sobre las relaciones que se establecieron entre ellos. Los testigos convocados daban fe de las devotas actitudes cristianas que demostraban tener los presuntos judaizantes.

De la actividad del Santo Oficio desarrollada en Burgos a finales del s. XV cabe mencionar el establecimiento de los inquisidores en la ciudad desde enero a junio de 1492 con el objeto de recoger testificaciones contra judaizantes. La visita no supuso ninguna amenaza para ellos, ya que se recogieron un total de ocho testificaciones, referidas todas ellas a conversos de otros lugares, bien de la comarca bien de otros lugares de los obispados de Osma y Cuenca. La mayoría de los testigos, sin embargo, son vecinos de Burgos, y entre ellos se encuentran varios judíos como Yudá Rabinuça, sastre y zurcidor, Jacó de Hara o la mujer de Salamón Micá; un moro, Alí de Córdoba, carpintero y hortelano ${ }^{33}$, y varios criados cristianoviejos.

En relación a las causas de fe que de estas u otras testificaciones pudieran seguirse no tenemos apenas ninguna noticia, salvo varios informes inéditos de mediados de s. XVI que se conservan en el archivo capitular de Burgos ${ }^{34}$. Estos se refieren al pleito que se trató sobre ciertos sambenitos de condenados, reconciliados y penitenciados por el Santo Oficio que habían estado expuestos en la Catedral y que fueron trasladados a la villa de Balbás, a cinco leguas de la ciudad, en el actual término de Los Balbases. En 1551 estos sambenitos habían sido colocados por orden del inquisidor de Valladolid, el licenciado Vaca, en la capilla de Santiago de la Catedral, provocando el disgusto del Cabildo y del Concejo burgalés, pues atentaba a la "bondad y christiandad» de la ciudad. En representación de ambas instituciones, el regidor Gregorio de Polanco, y el capiscol de la iglesia Diego Díez de Arceo Miranda, presentaban el 23 de septiembre de ese mismo año ante el Consejo de la Inquisición y al Inquisidor General una petición para que los quitasen de allí.

Según esgrimían en sus escritos, estos sambenitos se referían a los herejes que habían sido condenados en el auto de fe que se celebró en Balbás «más de çinquenta y çinco años a esta parte», es decir, ca. 1492-1493, procediendo en ello el obispo de Mondoñedo, Alfonso Suárez, que era por entonces inquisidor de Burgos. Al parecer, éste quiso primeramente celebrar el auto de fe en la ciudad - posiblemente sería uno de los primeros organizados-y llegó a colgar en la iglesia mayor de la catedral los sambenitos del mismo, "entre vnos pilares que están debaxo del relox de la yglesia mayor desta çibdad colgados en vnos cordeles». Pero las autoridades municipales se quejaron a los Reyes, porque la ciudad tenía cédula real «para que ningún auto de hexecuçión de ynquisiçión se hiziese en la dicha çiudad ni en su tierra e para que se quitasen los ábitos quel dicho inquisidor había puesto en la iglesia».

33 Vid. C. Carrete Parrondo, FIRC, II, pp. 159-162 y pp. 164.

34 ACB, Libro 61, fols. 1082-1096 y 1113-1122. 
Para justificar su petición, adujeron copia de algunos de los acuerdos municipales que se tomaron entre los años de 1493 a 1494 referidos a este asunto ${ }^{35}$. Según las actas de este período, la exposición pública de estos abitillos redundaba en «la disfamia de esta çiudad». Se encomendó a Hernando de Burgos y a Pedro Pardo que suplicaran a los Reyes Católicos que los actos inquisitoriales no se celebrasen en la ciudad porque «bernía a ellos muchos ynconbinientes e daños» y porque este tipo de ajusticiamientos «a esta çiudad toca muy poco". Una vez obtenido el privilegio de los Reyes ${ }^{36}$, se escribió al inquisidor Torquemada para informarle del mismo. Con todo ello, el Concejo consiguió que los sambenitos de estos condenados fueran colgados en Balbás. Con estos precedentes puede entenderse la indignación que supuso para los representantes locales su nuevo y ocasional traslado a Burgos en 1551. Insistían todos en que muchos sanbenitos no eran de personas naturales de Burgos, sino de vecinos advenedizos, por lo que poco ejemplar podía resultar su exposición para los habitantes de la ciudad.

Los informes de Gregorio de Polanco y de Diego Díez de Arceo incluyeron dos detalladas relaciones con los nombres de los condenados, tanto en el auto de Balbás como en otros posteriores, pero sin especificar las fechas de los mismos ${ }^{37}$. Gracias a ellas podemos confirmar la reducida actividad de la Inquisición en Burgos; aunque no por ello, menos violenta.

En el auto de Balbás fueron condenados veinticinco reos, todos ellos quemados en la hoguera, cinco de ellos ausentes; de diez de ellos se especifica que fue por el delito de criptojudaísmo. Es muy probable, sin embargo, que otras personas incluidas en esta primera relación nominal, también pudieran haber sido juzgadas por prácticas judaizantes aunque el delito no quedara finalmente reflejado en los lienzos que se colgaron. Es destacable el alto número de mujeres implicadas —un total de once- así como el predominio de oficios artesanales, muy afines al contexto burgalés. En 1551, Alonso de Leraña, de 78 años, un vecino muy antiguo de la ciudad y presentado como testigo en uno de los informes de probanza, reconocía incluso haber conocido algunos de los condenados: "a vn Hernán Trincado, tomador, e vn Juan de Burgos, pellejero, e a otro Juan de Burgos, sastre de ropa vieja y de una muger que se dezía Clara, a la Villa Nueva» ${ }^{38}$. Asimismo en esta primera relación se encuentran varios miembros del cabildo: el licenciado Sancho Sánchez de Frías, canónigo, y Sancho de Frías, racionero, ambos de muy probable ascendencia judeoconversa ${ }^{39}$.

\footnotetext{
35 Se trasladaron las siguientes sesiones: 3 de julio, 5, 19, 21 y 24 de diciembre de 1493; y 7 de enero de 1494. Cfr. J. A. Bonachía Hernando, «'Más honrada que ciudad de mis reinos ...': la nobleza y el honor en el imaginario urbano (Burgos en la Baja Edad Media)», p. 290, n. 144; y «La ciudad de Burgos en la época del Consulado (apuntes para un esquema de analisis de Historia urbana)», p. 144.

${ }^{36}$ No he podido localizarlo en los archivos de la ciudad. Se ha conservado una provisión relacionada con los reos huídos de la Inquisición que se incluye en apéndice 1.

37 Vid. apéndice 4.

38 ACB, Libro 61, fol. 1119 r.

39 Varios miembros de esta familia, como Fernando Sánchez de Frías, también estuvieron relacionados con el Cabildo. En una ocasión éste discutía con Pedro Márquez por haberle dicho «Vos sois ju-
} 
La segunda relación de sambenitos conservada está estructurada de forma diferente, aunque tampoco está fechada. En ella se incluye la mayor parte de los nombres de los condenados en el auto anterior - diecinueve de los veintinco-, distinguiéndose de los mismos mediante una pequeña abreviatura en el margen izquierdo, en referencia al auto de Balbás. Los nombres nuevos que se incorporan han de referirse, necesariamente, a las condenas realizadas con posterioridad al auto de Balbás pero en ningún caso más tarde de 1551, fecha en la que se produjo la visita del licenciado $\mathrm{Vaca}^{40}$ y en la que se elaborarían ambas relaciones de sambenitos como prueba presentada en el pleito por el Cabildo y Concejo burgaleses.

En esta segunda relación no se indica el delito por el que los reos fueron condenados, por lo que desconocemos si se abrió algún proceso por prácticas judaizantes durante la primera mitad del s. XVI. Excepcionalmente se especifica el delito de uno de ellos, el de Francisco de San Román, «quemado por luterano» y también la condición morisca de otros cinco condenados. Son un total de veintidos sambenitos nuevos con diez sentencias de reconciliación y doce de pena mayor en la hoguera.

Sirvan estas breves reflexiones y estos nuevos datos, que ofrezco en apéndice, como una aportación más a lo que aún queda por conocer acerca de la realidad judeoconversa burgalesa.

\section{IV}

\section{Apéndice documental}

1. Provisión dada por los señores reyes don Fernando y doña Isabel por la cual se manda que todos los corregidores y demás justicias de todas las ciudades, villas y lugares destos reinos y señoríos que tuviesen noticia dónde paran y asisten qualquier persona o personas que hayan sido castigados por el santo tribunal de la Inquisición, los prendan y ahorquen además de embargar y confiscar sus bienes. Zaragoza, 2 de agosto de 1498.

«Don Fernando e doña Ysabel por la gracia de Dios rey e reyna de Castilla [...] a los del nuestro Consejo e oydores de las nuestras abdiençias e alcaldes e alguaziles de la nuestra casa e Corte e Chançellería e a todos los corregidores asistentes alcaldes e alguaziles e otras justiçias qualesquier de todas las çibdades e villas e lugares de los nuestros reynos e señoríos e a cada vno de qualquier de vos

dío y marrano», vid. N. López Martínez, "Don Luis de Acuña, el Cabildo de Burgos y la Reforma», p. 258 n. 303. Cfr. también ACB, Libro 46, fol. 265, 15 de septiembre de 1470: testimonio de cómo este cabildo decidió seguir un proceso ante el prelado de Burgos, contra Rozas, hermano de Sancho Sánchez de Frías, canónigo, que apaleó ante la puerta real de esta iglesia a dicho prelado.

40 En otro lugar de la documentación se indican los nombres de los inquisidores que se asentaron en la ciudad después de la primera vez: «[fol. 1119r] fueron el licenciado Moriz, e después dél el dotor Albarado e por esta vitima, el licenciado Baca». 
en vuestros lugares e juridiçiones a quien esta nuestra carta fuere mostrada [...] salud e gracia. Sepades que los ynquisidores de la herética prauedad dados e diputados por nuestro muy Santo Padre e los sus delegados dellos en los dichos nuestros reynos e señoríos exerçiendo el ofiçio de la dicha ynquisiçión han fallado que muchas y diversas personas, pospuestos el temor de Dios, teniendo nombre de cristianos e aviendo reçibido agua de Espiritu Santo, han pasado e tornado a fazer los ritos e çerimonias de los judíos guardando la ley de Moysén e sus ritos e çerimonias creyendo en ella se saluar e han cometido otros delictos e herrores contra nuestra santa fe católica, relaxando aquellas al braço e justiçia seglar para que allí reçebiesen e reçiban la pena que por sus graves delictos mereçen. E por quanto algunas dellas se han avsentado e fuydo e se avsentan e fuyen destos nuestros reynos e señoríos e sus personas no han podido ser avidas ni se pueden aver para executar enellas la justiçia corporal y se han ydo y van a otras partes adonde con falsas e siniestras relaçiones e otras formas e maneras yndevidas han ynpetrado e ynpetran surreptiçiamente execuçiones, absoluçiones, comisiones, seguridades e otros preuillejos a fin de se exemir de las penas en que han yncurrido e de se quedar como quedan en los mismos herrores, e a tienta de se boluer e tornar a estos dichos nuestros reynos e señoríos para biuir e morar enellos, de lo qual si a ello se diese lugar se seguiría grande seruicio a Dios y escándalo a las ánimas de los fieles cristianos, por ende, queriendo extirpar tan grand mal de nuestros reynos e señoríos por lo que deuemos a Dios nuestro señor e a nuestra santa fee católica, mandamos a las dichas personas que así han sido o fueren condenadas por los dichos inquisidores y a cada vna dellas que no bueluan ni tornen a los dichos nuestros reynos e señoríos por alguna vía e manera, basa e raçón so pena de muerte e de perdimiento de bienes, la qual pena queremos e mandamos que por esse mismo fecho yncurran e queremos que la terçia parte de los dichos bienes sea para la persona que lo acusare e la terçia para la justiçia e la otra terçia para nuestra cámara. E por esta mandamos a vos, las dichas nuestras justiçias e a cada vno e qualquier de vos en vuestros lugares e juridiçiones, que cada e quando supierdes que alguna de las personas susodichas estouieren en algund lugar de vuestra juridiçión sin esperar otro requerimiento, vayades adonde la tal persona estouiere e le prendades el cuerpo e luego sin dilaçión executéys e fagáys executar a su persona e bienes las dichas penas por nos puestas segund que dicho es, no enbargante qualesquier execuçiones, reconçiliaçiones e seguridades e otros preuillejos que tengan, los quales en este caso quanto a las penas susodichas non les pueda sufragar. $Y$ esto vos mandamos que fagades e cumplades así so pena de perdimiento e confiscaçión de todos vuestros bienes y en esta indina pena queremos que yncurran qualesquier otras personas que los tales reçebtaren o encubrieren o supieren dónde están e non lo notificaren a vos, las dichas nuestras justiçias. E mandamos a los ynfantes, duques, marqueses, condes, prelados, ricos omes, marqueses [...], alcaides de los castillos e casas fuertes e llanas e a todos los conçejos, justiçias, regidores, caualleros, escuderos, ofiçiales e omes buenos de todas las çibdades e villas e lugares de los dichos nuestros reynos e señoríos e a otras qualesquier personas de qualquier ley, estado, condición, preheminençia o 
dignidad que sean a cada vno e qualquier dellos e sí para fazer e conplir e executar lo susodicho ovierdes menester, fauor e ayuda vos den e fagan dar todo el fauor e ayuda que les pidiérdes e menester ovierdes sin poner enello escusa ni dilaçión alguna so las penas que vos les pusierdes de nuestra parte, las quales nos, por la presente les ponemos e avemos por puestas. E para fazer conplir e executar todo lo que dicho es e cada vna cosa e parte dello por la presente vos damos poder conplido con todas sus ynçidençias e dependençias emergençias anexidades e conexidades e porque lo susodicho sea público e notorio mandamos que esta nuestra carta sea pregonada por las plaças e mercados e otros lugares acostumbrados de las çibdades e villas e lugares de los dichos nuestros reynos e señoríos por boz de pregonero e ante escriuano público por manera que venga a notiçia de todos e ningunas ni algunas personas puedan dello pretender ynorançia e los vnos ni los otros non fagades ni fagan ende al. Dada en la çibdad de Çaragoça a dos días del mes de agosto, año del nasçimiento de nuestro saluador Ihesu Christo de mill e quatrocientos e noventa e ocho años. Rúbrica: Yo el Rey. Yo la Reyna. Yo Miguel Peres de Almaçán, secretario del Rey e de la Reyna, nuestros señores, la fize escreuir por su mandado".

AMB, Historica 3243

\section{Relación en lo de los sambenitos. Año de 1553}

«El licençiado Baca, vno de los ynquisidores hordinarios de Valladolid al tiempo de su partida desta çiudad de Burgos hiço poner en la capilla de Santiago los san benitos que al presente enella están, de lo qual la çibdad y yglesia se agrabió mucho y ansí fueron el señor Gregorio de Polanco, regidor desta çibdad y Diego Díez de Arceo Miranda, capiscol ${ }^{41}$, e la yglesia della a Valladolid a procurar con el arçobispo de Sevilla y con los señores del Consejo de la Ynquisiçión mandasen quitar los dichos sanbenitos.

Tratando el negocio con los dichos señores arçobispo y los del Consejo de la Ynquisiçión se entendió que el arçobispo no abía mandado poner los dichos sanbenitos ni abía dello sabido nada, antes el dicho liçençiado los avía puesto porque los señores del Consejo le avían mandado que al tiempo que bisitase alguna çibdad o lugar renobase los san benitos y si no estubiesen puestos los pusiese y asý el arçobispo dio a hentener le pesaba mucho se hubiesen puesto en esta çibdad y dixo en todo lo que en él fuese procuraría de dar contentamiento a la yglesia y çibdad mandándolos quitar, pero que no se podría en el negocio haçer nada asta que el licenciado Baca, que a la sazón estaba avsente de Valladolid, viniese y así se procuró biniese e como bino y dixo al arçobispo y a los señores del Consejo la raçón por que los avía puesto.

41 O 'chantre'. Encargado de dirigir el oficio cantado en la catedral, vid. S. de Covarrubias, Tesoro de la lengua castellana o española, Barcelona 1943, s.v. «capiscol», p. 297. 
Después de lo qual soliçitando los dichos Polanco y Capiscol al arçobispo para que mandase quitar los dichos sanbenitos, les mandó diesen vna petiçión en Consejo diçiendo él se allaría presente al probar della y faboreçería el negoçio.

Diose la dicha petiçión y una de las cosas que enella se dixo para justificaçión del negoçio fue que antiguamente fueron puestos estos sanbenitos en la Yglesia Mayor desta çiudad y después mandados quitar por la reyna doña Ysabel, de gloriosa memoria, y puestos en la villa de Valvás, donde agora están, como más largamente se berá por la dicha petiçión, la qual puesta en Consejo, fue respondido que la çibdad y yglesia muestre la claridad de lo que dize y que se le ará justiçia. Y mandaron a los secretarios del Consejo de la Inquisiçión y de la Ynquisiçión ordinaria de Valladolid [roto: sa]-casen en sus registros toda la claridad que çerca de dicho negoçio hubiese y la truxesen a los señores del Consejo.

[fol. 1082 v] Bista la respuesta dada, los sobredichos Polanco y Capiscol escribieron a la yglesia y çibdad dando aviso de lo que pasaba y encargando se hiçiese diligençia de buscar en los arquibios la cédula de la reyna doña Ysabel o alguna claridad del negoçio así por testigos como por escripturas.

Hecha la dicha diligençia en los libros del Conzejo de la cibdad pareçieron çiertos autos por donde consta cómo antiguamente se pusieron los dichos san benitos, de lo qual la çibdad se agravió y a la causa ynbió a çiertas personas para negoçiar con la reyna doña Ysabel los mandase quitar, cómo lo negoçiaron y así por los dichos avtos consta del regoçijo que se hiçieron quando se quitaron y los dineros que se dieron a los que fueron a negoçiarlo, lo qual todo se probó por testigos de oýdas y algunos de bista y estos auctos sacados por la justiçia y la probança echa sin parte enbió la çibdad al dicho señor Polanco, el qual lo presentó juntamente con el dicho Capiscol y presentado todos dos ynstaron por la espidiçión de negoçio y por más que soliçitaron no pudieron açer con el arçobispo y oidores le despachasen a causa de la partida de la Corte para Madrid y de muchos negocios que en la partida tubieron. $Y$ entre ellos vno de vn canónigo de Sevilla que está preso por la Ynquisiçión y a la causa remitieron el negocio para Madrid.

El dicho Capiscol quando por mandado de los señores del cabildo fue a Madrid a la congregaçión llebó a mí encargado este negocio y por tratalle con más avtoridad se juntó con el señor Pedro de Melgosa, procurador de Cortes, para soliçitalle y así todos dos ablaron dibersas vezes al arçobispo de Sevilla y a los señores del Consejo de la Ynquisiçión, suplicándoles por la expidiçión de negoçio y al fin todos se resolbieron de esperar al señor don Diego de Córdoba, vno de los del Consejo que a la saçón avía quedado en Valladolid, bisitando la Chançellería por mandado de su magestad.

[fol. $1083 \mathrm{r}$ ] Benido el señor don Diego y bisto todo lo alegado y presentado por el arçobispo y él y los demás del Consejo, mandaron dar treslado de todo al fiscal y que respondiese como respondió. 
De aber mandado dar el dicho treslado al fiscal los dichos Melgosa y Capiscol se agraviaron mucho con el arçobispo y los del Consejo, los quales dieron a entender lo açían por mejor por haçer la cosa con parte casi diçiendo los mandarían quitar con solo lo presentado con que se hiçiese su parte sacando las escripturas presentadas y açiendo la probança hecha contando al fiscal.

Hentendido esto por los dichos Melgosa y Capiscol procuraron de sustançiar el prozeso con el fiscal y asý el dicho Capiscol, después de aber presentado poder bastante de la yglesia, sustançió el prozeso con el dicho fiscal asta la conclusión dél y por no estar concluso con la çibdad por no aberse presentado por su parte poder, no hiço las diligençias nescesarias, pero antes que se partiese se presentó el poder de la çibdad y el procurador della y ha sustançiando el proçeso con el dicho fiscal en su nombre y así debe de estar concluso con todos. Todo lo sobredicho constará más largamente por el proceso, el qual está en poder del secretario lohan Martínez de la Sao.

El dicho Capiscol al tiempo de la partida de vuestra ynstruçión a Antonio de Quintela, solicitador del cabildo en el Consejo Real, çerca de lo que se avía de hazer en este negoçio diçiendo como llegase a esta çibdad le aría ynbiar dineros para lo nesçesario, los quales el cabildo nunca le a ynbiado y así a lo que se crey el dicho Quintela no abía fecho más diligençia.

El que hubiere de tratar este negocio podrá ser ynformado de todo lo que cumple desta ynformación y del proçeso y del dicho Quintela, al qual es menester escrebyr de parte del cabildo así por estar ynformado de negocio como por ser su procurador para azer los avctos.

[fol. 1083v] Lo que pareçe cumple haçer en este negocio es procurar de parte de la yglesia y cibdad se admitan a la prueba y admitidos açer su ynterrogatorio para probar lo nescesario conforme a lo alegado para probar por testigos todo lo que está probado y más si fuere posible y tanbién despachar vna compulsoria para sacar de nuebo çitando al fiscal todo lo que está en los libros del Conzejo de la çibdad porque, fecho esto y presentada y solicitando el negoçio por parte de la cibdad yglesia como es raçón se soliçite, no tengo duda ninguna sino que estas ynsignas en bista y rebista se mandarán quitar y que se estén en Balbás donde están y asta la diligençia que aquí digo se haga no me pareçe ay nesçesidad descrebir al arçobispo ni al señor don Diego de Córdoba ni a nadie».

ACB, libro 61, fol. 1082r - 1083v

3. Consulta presentada en contra por Gregorio de Polanco y Diego de Arceo. Valladolid, 23 de septiembre de 1551.

«Muy principales señores: Gregorio de Polanco, regidor de la çibdad de Burgos e Diego Diez de Arzeo, capiscol de la Santa Yglesia de la dicha çibdad, personas nombradas e deputadas por la dicha yglesia y çibdad, dezimos que ya 
vuestra alteza sabe cómo el liçençiado Baca, ynquisidor desta villa y su partido, fue a la çibdad de Burgos y en la yglesia mayor della puso çiertos sanbenitos de reconçiliados e penitençiados por el Santo Offiçio que ha muchos años que fueron penitençiados e se hizo auto de la fee contra ellos en la villa de Valuás, que es a nuebe leguas de la dicha çibdad donde los dichos sanbenitos han estado y están de más de çinquenta y çinco años a esta parte y en otras partes y lugares destos reinos, de lo qual se a seguido e resultado grand escándalo, lo vno porque los dichos sanbenitos, avnque en algund tiempo fueron puestos allí por justos e católicos respectos, se volbieron a la dicha villa de Valuás donde hasta agora han estado; lo otro porque lo susodicho es grand nobedad atento que agora no ay causa para que se pongan, pues en la dicha çibdad ay tanta bondad e cristiandad; lo otro porque por ellos son ynfamados muchos católicos y fieles christianos que biben christiana y católicamente e vibieron sus padres y abuelos y otros anteçesores, y avnque por abentura tengan alguna dependençia de los tales penitençiados no han de ser ynfamados ni tal permite ni quiere este Santo Offiçio ni el derecho; lo otro porque el auto de la fee que contra los dichos penitençiados se hizo fue hecho en la dicha villa de Valuás y en otras partes destos reinos y allí han estado los dichos sanbenitos y están de presente y ponerlos donde nunca han estado sería más penar e infamar a los católicos que no que sirbiese de algund fin; lo otro, porque el dicho auto se hizo en la dicha villa de Valuás por dispusiçión e mandamiento de los señores Reyes Católicos, de gloriosa memoria, vuestros progenitores e teniendo respecto a los muchos seruiçios e honra de la dicha çibdad e linpieza e christiandad della; lo otro porque los que fueron castigados e penitençiados por el dicho avto no fueron naturales de la dicha çibdad, avnque algunos heran adbenedizos y vezinos della e nuebamente avezindados enella e personas baxas e soezes e tales que de ponerse sus sanvenitos en la dicha çibdad ningund castigo ni exemplo se seguía para los vezinos de la dicha çibdad que heran nobles y onrrados y católicos christianos; lo otro, porque después de aberse fecho el dicho auto de la fe en la dicha villa de Baluás se trató de poner los dichos sanbenitos en la dicha yglesia mayor de la dicha çibdad de Burgos y por no ser los dichos penitençiados como dicho es naturales de la dicha çibdad a ynstançia de la dicha çibdad los dichos señores Reyes Católicos [fol. $1096 \mathrm{v}$ ] mandaron que se boluiesen y quedasen en la dicha yglesia de la dicha villa de Baluás. Y siendo esto ansí ni es justo que se faga novedad [...]; lo otro porque, pues el Santo Officio, de término que el dicho avto se hiziese en la dicha villa de Baluás y allí han estado y allí se pusieron los dichos sanbenitos tanto tiempo notorio es que aquello se hizo muy remirado e acordando y entendiendo que aquello era lo que más convenía a nuestra santa fee cathólica y fazer agora novedad enello no viendo causa pública y pattente sería engendrar como se a engendrado grande escándalo en los cathólicos pensando que en la dicha çibdad ay algunos herrores o cosas yndevidas. Lo otro porque, avnque alguna que sea ya dicho vecino de la dicha çibdad, aya seydo de pocos años a esta parte penitenciado o castigado por el dicho Santo Oficio, aquel no pecó en la dicha çiudad ni en su juridiçión ni avn en estos reynos y las ynsignias del delinquente antel delito se han de poner donde delinque 
y no en otra parte; lo otro porque de más de la ynfamia personal que se syguiría a los vezinos de la dicha çiudad, ningund natural destos reynos ni estrangero dellos contrataría con vezinos de la dicha çiudad, lo qual sería grand daño a la dicha parte destos reynos, pues la mayor parte de la contratación dellos es de vecinos de la dicha çiudad. A lo qual para tractamiento [sic] tuvieron respeto los dichos señores Reyes Cathólicos y los del Consejo de la Santa e General Inquisición que a la sazón que el dicho auto de la fee se hizo resydían en el dicho real Consejo e asý lo dispuso primero [...] el reverendísimo inquisidor general que a la sazón era segund lo [..] firman personas antiguas [...] de la dicha çiudad y así creemos que deve de estar en los registros del Santo Officio de la Inquisición de esta villa, pues como dicho es el dicho auto no se hizo en la dicha villa de Baluás syendo la dicha çiudad caueca [sic] de obispado. Por ende, a vuestra alteza pedimos e suplicamos en el dicho nombre mande remover y quitar los dichos sant benitos de la dicha yglesia mayor de la dicha ciudad de Burgos y boluerlos a remouerlos en la dicha yglesia de Valuás donde [...] han estado».

ACB, libro 61, fols. $1096 \mathrm{r}-1096 \mathrm{v}$

\section{Relación de Acusados y sambenitos}

\subsection{Auto de Balbás}

«[fol. 1092r] Los sanbenitos que ay en Balbás y de la manera que están son los siguientes:

[1] Burgos el liçençiado Sancho Sáenz [sic] de Frías, canónigo de Burgos, herético condenado.

[2] Burgos

Simón Sánchez, sastre, herético condenado.

[3] Burgos

Pero Garçía, texedor de lienços, herético condenado.

[4] Burgos

Ysabel Garçía, muger de Sancho Garçía de la Vida ${ }^{42}$, herética condenada.

[5] Burgos

Juan de Burgos, sastre, herético judaizado ${ }^{43}$.

42 De 1484 datan las actividades del mercader burgalés, trapero y tendero en paños Pedro de la Vida, vid. ACB, Vol. 44, fol. 14.

43 En 1465 fue testigo en el censo otorgado por Alfonso Rodríguez de Palencia, canónigo, y Juan Alonso de Formallaque, racionero, a favor de Juan Martínez de Montoya, capellán del número, sobre unas casas situadas en el Mercado Mayor por renta anual de 1850 mrs. y dos pares de gallinas, según ACB, RR-19, fol. 34 . 
[6] Burgos

Mari Rodriguez, muger de Juan Rodriguez, juglar, herética condenada.

[7] Burgos

La suegra de Garçía Avitero, herética condenada por ausente.

[8] Burgos

Ysabel, muger de Diego Merino, herética declarada.

[9] Burgos

Catalina González, muger que fue de García González de Aranda, herética judaizada.

[10] Valbás

Fernán Sánchez de Villadiego, herético judaizado.

[11] Burgos

Juan de Antequera, que fue moro, herético condenado.

[fol. $1092 \mathrm{v}$ ]

[12] Burgos

Sancho de Frías, razionero que fue en la yglesia de Burgos, hijo del liçençiado Frías, herético condenado por ausente.

[13] Burgos

Maestre Pedro, herético condenado por ausente.

[14] Burgos

Hernán Trincado, tanador ${ }^{44}$, herético condenado.

[15] Burgos

Mari Garçía, la espejera, herética judaizada.

[16] Burgos

Francisco de Burgos, questor ${ }^{45}$, herético judaizado.

[17] Burgos

Francisco de Valladolid, herético condenado por ausente.

[18] Burgos

Fernando de la Torre, herético condenado por ausente.

[19] Burgos

Catalina González, muger de Juan González de Herrera, herética judaizada.

[20] Burgos

Clara Sánchez, corredora e torzedora de seda, herética judaizada.

44 Curtidor. Cfr. Juan Sánchez Trincado, en ACB, Lib. 15, fol. 39-40, agosto 1482.

45 Persona que pide limosna con fines benéficos. 
[21] Burgos

Graçia de Arçiniega, hermana de Diego Merino, quemado, herética judaiza[da].

[22] Burgos

Juan de Burgos, pellegero, herético judaizado.

[23] Burgos

Mari Garçía, muger de Garçía Capabro, herética judaizada.

[24] Burgos

Mari Garçía, madre de maestre Pero, herética condenada.

[fol. $1093 \mathrm{r}]$

[25] Garçi Fernández, çapatero, herético condenado.

\subsection{Segunda relación de sambenitos}

[fol. $1094 \mathrm{r}$ ]

[1] Fernando de Rybera, tabernero, vecino de Burgos, quemado.

[2] Grabiel de Caste, pellejero, vecino de Burgos, quemado.

[B] Gracia de Arciniega, muger de Fernando de Frías, vecina de Burgos, quemada.

[3] Gonzalo de Contreras, vecino de Burgos, quemado.

[4] Juan de Contreras, vecino de Burgos, quemado.

[B] Ysabel García, muger de Sancho de la Vyda, vecina de Burgos, quemada.

[B] Juan de Antequera, vecino de Burgos, quemado (en otra letra: en el de Balvás, dize que fue moro).

[B] Ysabel, muger de Diego Merino, vecina de Burgos, quemada.

[5] Juan de Guzmán, morisco, vecino de Burgos, quemado.

[6] María de Guzmán, muger de Juan de Guzmán, vecina de Burgos, quemada.

[B] Juan de Burgos, pillejero, vecino de Burgos, quemado.

[7] Juan Franzés de Fresneda, vecina de Burgos, quemado.

[8] Ynés García, muger de Sancho de Palencia, vecina de Burgos, quemada. [fol. $1094 \mathrm{v}]$

[B] La suegra de García Abitero, vecina de Burgos, quemada. 
[B] María Rodríguez, muger de Juan García, joglar, vecina de Burgos quemada. (en otra letra: en el de Balbás dize muger de Juan Rodríguez, joglar).

[B] Maestre Pero Abanseca, vecino de Burgos, quemado.

[B] Mari García, la espexera, vecina de Burgos, quemada.

[B] Pero de Truxillo, vecino de Burgos, quemado.

[B] Sancho de Frías, racionero, vecino de Burgos, quemado (en otra letra: en el de Balbás, dize por absente).

[B] Simón Sánchez, sastre, vecino de Burgos, quemado.

[B] Clara Sánchez, corredora, vecina de Burgos, quemada.

[9] Beatriz García de Estella, vecina de Burgos, quemada.

[B] Cathalina González, muger de García Gonzales de Aranda, vecina de Burgos, quemada.

[B] Catalina Gonzales, muger de Juan Gonzales de Tixera, vecina de Burgos, quemada (en otra letra: en el de B. dize de Herrera).

[fol. $1095 \mathrm{r}$ ]

[10] Diego Godil, mercader, vecino de Burgos, quemado.

[B] El licenciado Sancho Sánchez de Frías, vecino de Burgos, quemado, (en otra letra: dize en el de Balbás, canónigo de Burgos).

[B] Francisco de Burgos, sastre y echacuerbo ${ }^{46}$, vecino de Burgos, quemado, en el de Balbás dize Juan de Burgos.

[11] Francisco de San Román, vecino de Burgos, quemado por luterano.

[12] Fernando de Luria, vecino de Burgos, quemado.

[B] Fernando de la Torre, vecino de Burgos, quemado.

[B] Fernando Tryncado, vecino de Burgos, quemado. [al margen: 39 quemados]

[13] Ynés de Burgos, muger de Alonso de Medina, vecina de Burgos, reconciliada.

[14] Juana Rodríguez, madre de Donza, vecina de Burgos, reconciliada.

[15] Lesmes de Montose, morisco, vecino de Burgos, reconciliado.

\footnotetext{
46 Según S. de Covarrubias, Tesoro, 383 b, «los que con embelecos y mentiras engañan los simples, por vender sus ünguentos, azeites, yervas, piedras y otras cosas que traen, que dizen tener grandes virtudes naturales».
} 
[16] Lope de Pampliega, morisco, vecino de Burgos, reconciliado.

[17] Martín de Enzinas, morisco, vecino de Burgos, reconciliado.

[18] Margarida de Logroño, vecina de Burgos, reconciliada.

[fol. $1095 \mathrm{v}]$

[19] María Rodríguez, muger de Grabiel de Soto, físico, vecina de Burgos, reconciliada.

[20] María González, madre de Catalina de Toledo, vecina de Burgos, reconciliada.

[21] Fernando de Arébalo, vecino de Burgos, reconciliado.

[22] Gregorio de Muñoz, morisco, vecino de Burgos, reconciliado.

[al margen: 10 reconciliados].

Los sanbenitos que están en Balbás son 25 de los quemados y los 24 dellos son de Burgos y el vno de Balbás. Destos 24 están puestos los 18 en Burgos por manera que dexaron de ponerse seys sanbenitos y pusieron de otra parte a cumplimiento de los 21 de arriba, por manera que pusieron de otra parte que de la quema de Balbás 13 sambenitos de quemados entre los quales están los Contreras.

Reconciliados ay solamente en Balbás 3, los quales no se pueden leer pero presúmese que estos se pusieron en Burgos en los diez que agora están asý que están puestos de nuevo sin los de Valbás 7 sanbenitos».

ACB, libro 61, fols 1092r 1095v. 